\title{
SOUTHERN STARS
}

The cities of Australia and New Zealand represent a mix of scientific strengths, and their cumulative contributions have seen the region's research reputation flourish.

\section{AUSTRALIA}

Australia's two most populous states, New South Wales and Victoria, contributed the most to the country's output of high-quality natural science in 2015. Australia placed 12th in the global index ranking last year.

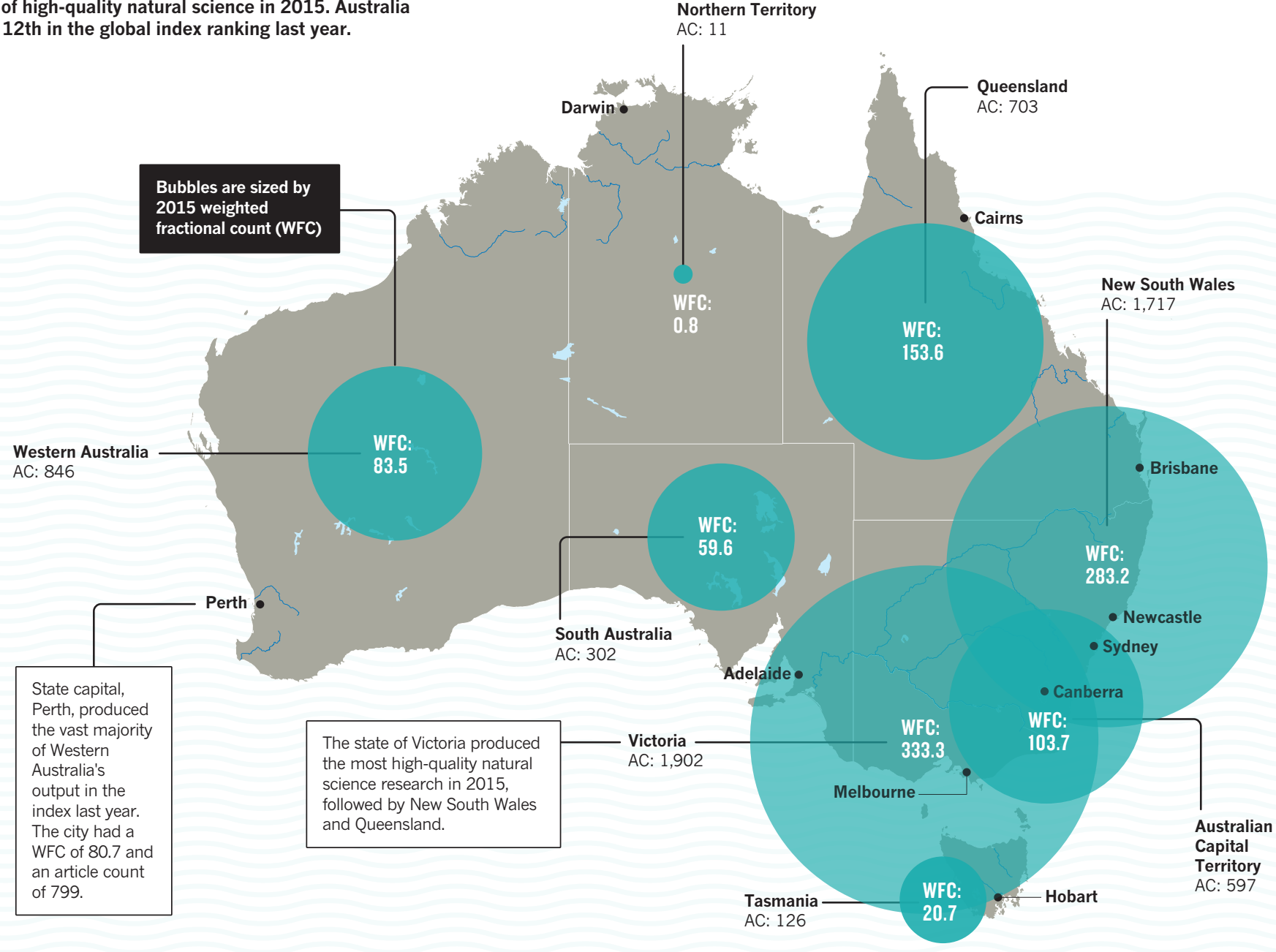

\section{OUTPUT OVER TIME}

Australia's contribution to the index, measured by WFC, has increased, while New Zealand's output has declined between 2012 and 2015. The total number of articles included in the index increased for both countries.

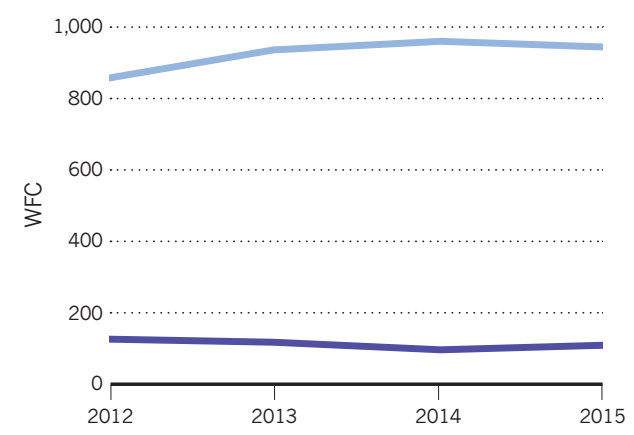

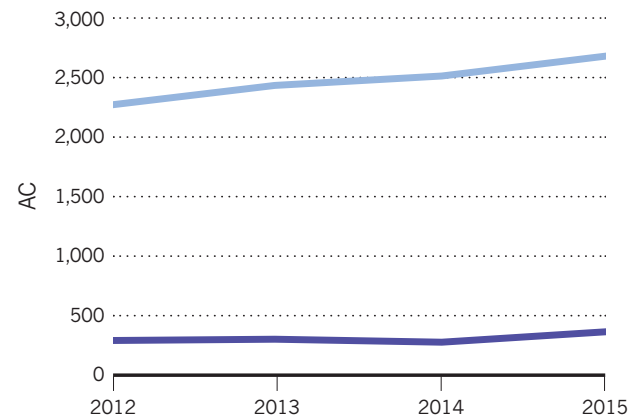


Index metrics:

Article count (AC): A country or institution's article count is the number of articles in the index that have at least one author from that country or institution. Weighted fractional count (WFC): the weighted fractional count measures the contribution of institutions to articles in the index.

Read more on page S77.

\section{NEW ZEALAND}

Five New Zealand cities drove the country's output of high-quality natural science in 2015. The country placed 30th in the global index ranking last year.
New Zealand map at

$200 \%$ size (relative

to Australia)

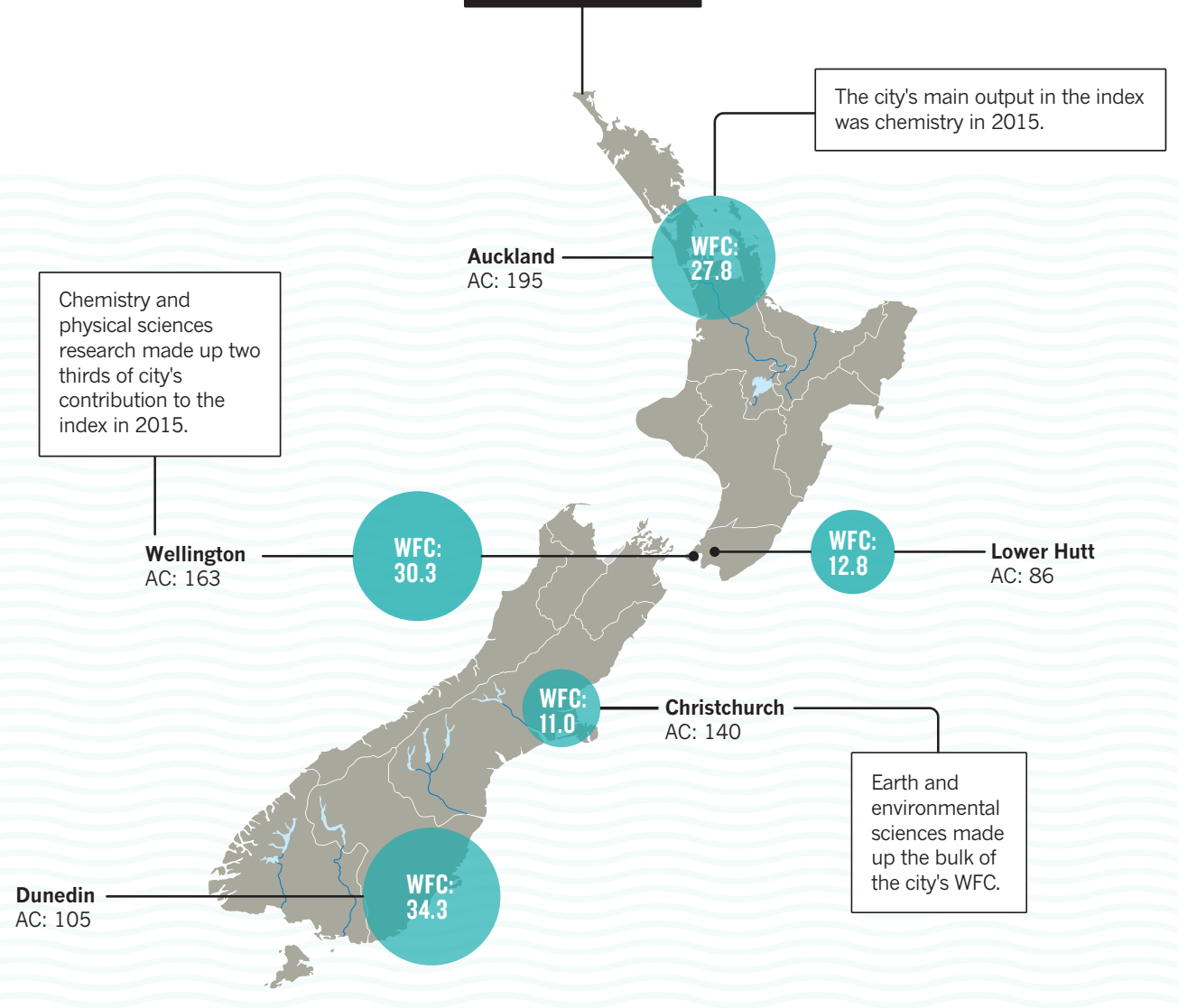

\section{SUBJECT SPLITS}

Australia's greatest contribution to the index in $\mathbf{2 0 1 5}$ was in life sciences, while New Zealand excelled in Earth and environmental sciences.

\section{Chemistry}

Earth and environmental sciences

Life sciences

Physical sciences

* As subjects may overlap, the sum of the subject area As subjects may overlap, the sum of the subject area

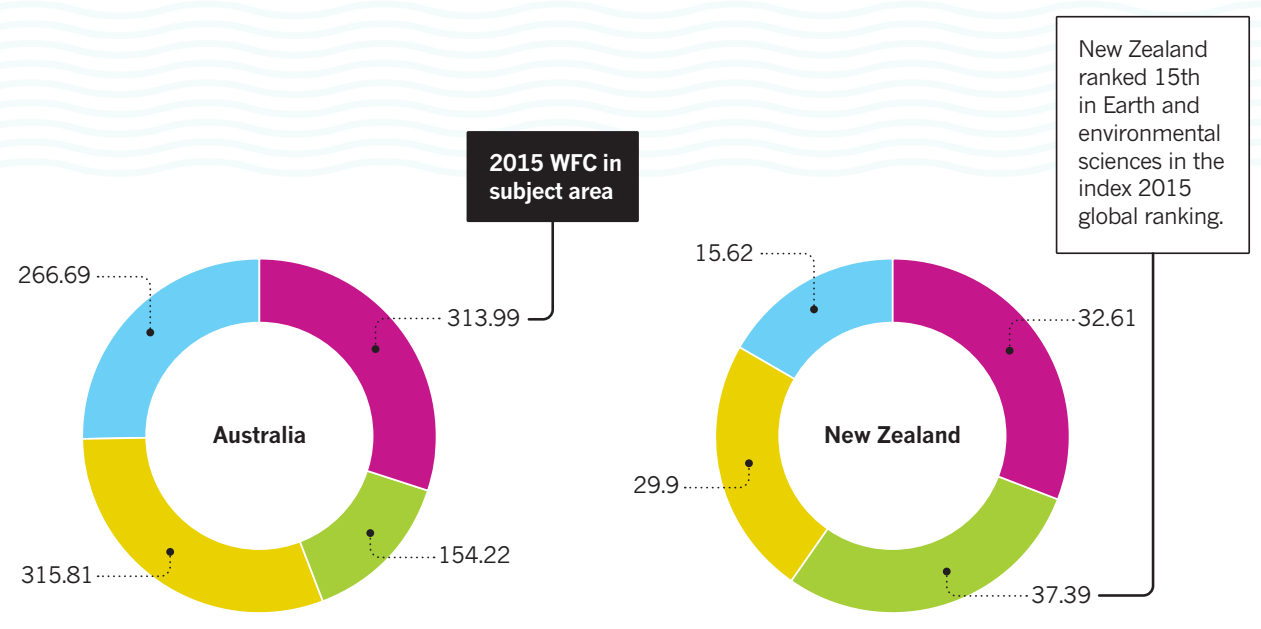

